Fetal Diagnosis and Therapy
Fetal Diagn Ther 2018;43:241-249

DOI: $10.1159 / 000480232$
Received: June 11, 2017

Accepted after revision: August 7, 2017 Published online: October 28, 2017

\title{
Noninvasive Sampling of the Intrauterine Environment in Women with Preterm Labor and Intact Membranes
}

\author{
Teresa Cobo ${ }^{a, b}$ Marian Kacerovsky ${ }^{\text {c, } d}$ Bo Jacobsson ${ }^{\text {e, }}{ }^{\text {f }}$ \\ a BCNatal-Barcelona Center for Maternal-Fetal and Neonatal Medicine (Hospital Clínic and Hospital Sant Joan de \\ Déu), Fetal i+D Fetal Medicine Research Center, Institut d'Investigacions Biomèdiques Agustí Pi I Sunyer (IDIBAPS), \\ University of Barcelona, and ${ }^{b}$ Centre for Biomedical Research on Rare Diseases (CIBER-ER), Barcelona, Spain; \\ 'Biomedical Research Center, University Hospital Hradec Kralove, Hradec Kralove, and d Department of Obstetrics \\ and Gynecology, Faculty of Medicine in Hradec Kralove, Charles University in Prague, Prague, Czech Republic; \\ eDepartment of Obstetrics and Gynecology, Sahlgrenska Academy, University of Gothenburg, Gothenburg, \\ Sweden; ${ }^{f}$ Department of Genetics and Bioinformatics, Area of Health Data and Digitalisation, Norwegian Institute of \\ Public Health, Oslo, Norway
}

\section{Keywords}

Preterm labor - Genital sampling - Intra-amniotic infection . Intra-amniotic inflammation · Histological chorioamnionitis

\begin{abstract}
Spontaneous preterm birth has enormous consequences for newborns, children, and families. Intra-amniotic inflammation (IAI) is the leading cause of spontaneous preterm delivery, mainly at earlier gestational ages. Amniocentesis is the only method used to identify IAI in clinical practice. Although it is an invasive procedure with a very low risk of complications, many women and physicians are hesitant about amniocentesis on this indication. This has been an incentive to explore $\mid \mathrm{AI}$ and the intra-amniotic environment through noninvasive techniques, such as sampling cervical mucus, vaginal fluid, or maternal blood. With this overview, we aim to provide a concise update on the state of the art of the noninvasive sampling of the intrauterine environment in women with preterm labor and intact membranes. So far, it is unknown whether this screening helps improve our knowledge about the impact of IAI on the neonatal and long-term outcome, but we believe it merits this review.
\end{abstract}

(c) 2017 S. Karger AG, Basel

\section{KARGER}

() 2017 S. Karger AG, Basel

E-Mail karger@karger.com

www.karger.com/fdt

\section{The Problem}

The earlier the symptoms of preterm labor (PTL) with intact membranes occur during pregnancy, the higher the involvement of intra-amniotic inflammation (IAI) in the physiopathology of spontaneous preterm delivery. Women with IAI deliver after a short latency and their premature babies suffer worse neonatal and long-term outcome [1-4] than those born at term.

IAI, with a prevalence of $30-50 \%$ in women with PTL [1-4], can occur without any clinical suspicion of chorioamnionitis and can develop in different ways. The most common, in 10-14\% [5-7], is through microbial invasion of the amniotic cavity (MIAC). MIAC elicits an inflammatory response detectable in the amniotic fluid. Specific motifs on the surface of the microorganism, pathogenassociated molecular patterns, bind to innate immune system molecules termed pattern recognition receptors and activate signaling cascades that generate IAI. Cytokines (e.g., interleukin [IL]-6 and IL-18) and chemokines (e.g., IL-8 and monocyte chemoattractant protein-1 [MCP-1]) are the main reported components of IAI pathophysiology. These proteins induce chemotaxis of 


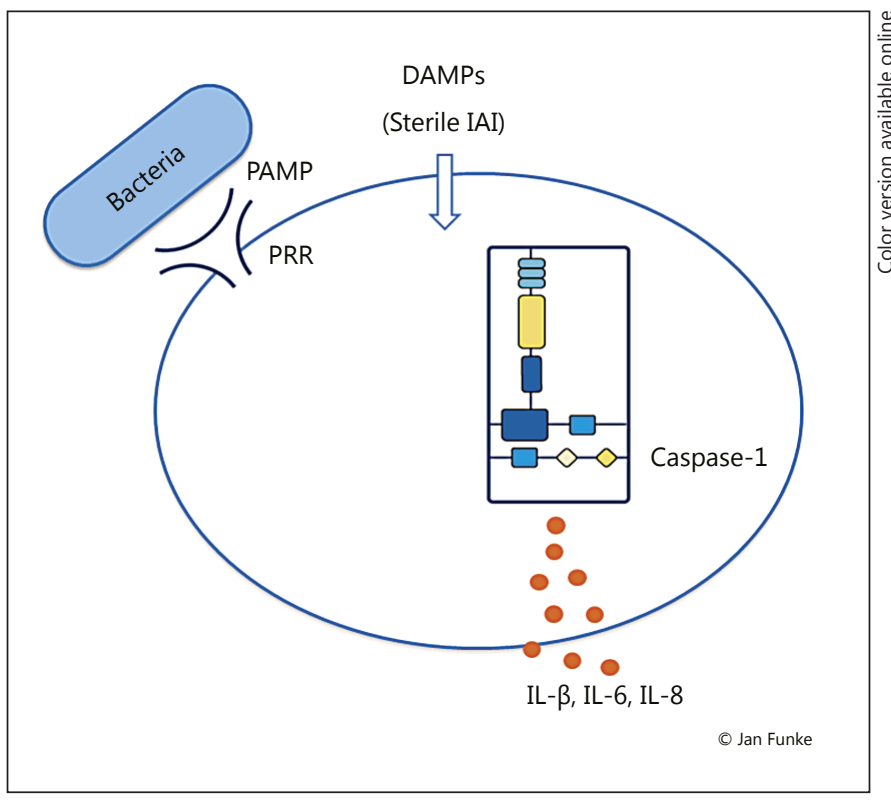

Fig. 1. Physiopathology of intra-amniotic inflammation.

neutrophils and macrophages from the uterine wall and enhance their migration to the placenta and fetal membranes, leading to acute histological chorioamnionitis (HCA). Other mechanisms involved are related to endogenous mediators (danger-associated molecular patterns or "alarmins") [8] released from the placenta and fetal membranes into the amniotic fluid. These "alarmins" trigger IAI through the same system of pattern recognition receptors as in MIAC, but instead leading to "sterile" IAI in 11-27\% of women with PTL [2, 9] (Fig. 1).

There is still no consensus about the terminology used to define these subclinical conditions. MIAC is currently most commonly diagnosed by isolation of microorganisms in the amniotic fluid [5]. However, a MIAC diagnosis does not clarify whether or not IAI will result from the microbial invasion. Other authors have used the term "intra-amniotic infection" to denote MIAC associated with IAI [2]. Recently, Romero et al. [9] suggested a clearer classification, defining 4 subgroups in relation to MIAC and IAI: (1) MIAC and IAI (microbial-associated IAI), (2) IAI without MIAC ("sterile" IAI), (3) MIAC without IAI (MIAC alone or "colonization") and, finally, (4) the negative group with neither MIAC nor IAI (Fig. 2). According to this terminology, microbial-associated IAI is found in approximately $11 \%$ of women with PTL and "sterile" IAI is found in $26 \%$ [2,9]. However, the reported proportion of women with "sterile" IAI varies according to the sensitivity of the applied microbial detection technique.

So far, amniocentesis is the only method used to identify IAI in clinical practice; it is an invasive procedure. However, many women and physicians are hesitant about amniocentesis on this indication, leading to insufficient knowledge of the clinical impact of IAI. The lack of clinical acceptance of amniocentesis has been an incentive to explore IAI and the intra-amniotic environment through alternative and noninvasive techniques, for instance by sampling cervical mucus, vaginal fluid, or maternal blood. We, as physicians, already have experience in noninvasive techniques to predict other outcomes [10-12]. We wondered whether noninvasive sampling of the intrauterine environment might be an alternative strategy to amniocentesis (Fig. 3). With this overview, we aim to ascertain whether noninvasive sampling might help us to identify women with infection or IAI who might really benefit from an amniocentesis. We present a summary of the current knowledge about cervical mucus, vaginal fluid, and maternal blood as surrogates for amniotic fluid sampling for MIAC, IAI, and HCA prediction in women with PTL.

\section{The Influence of Cervical Environment}

From a pathophysiological perspective, cervical mucus creates unique physical and immunological conditions during pregnancy that involve the innate and adaptive immune systems [13].

Its most relevant immunological role is to act as an effective barrier to vaginal bacteria, inhibiting ascending infection from the lower genital tract. Indeed, cervical mucus glycoproteins represent a structural framework to which growth factors, immunological proteins and antimicrobial peptides such as lectins, cytokines, and chemokines are attached.

Fibroblasts and other immune cells, such as T cells, dendritic cells, and macrophages, are responsible for the production of cervical cytokines and chemokines. The vaginal microbiome is responsible for modifying the levels of these inflammatory proteins [13].

\section{The Vaginal Microbiome Influence}

A unique feature of human vaginal epithelium is its permeability to microbes and cellular and molecular mediators of immune defense, promoting the growth of an 


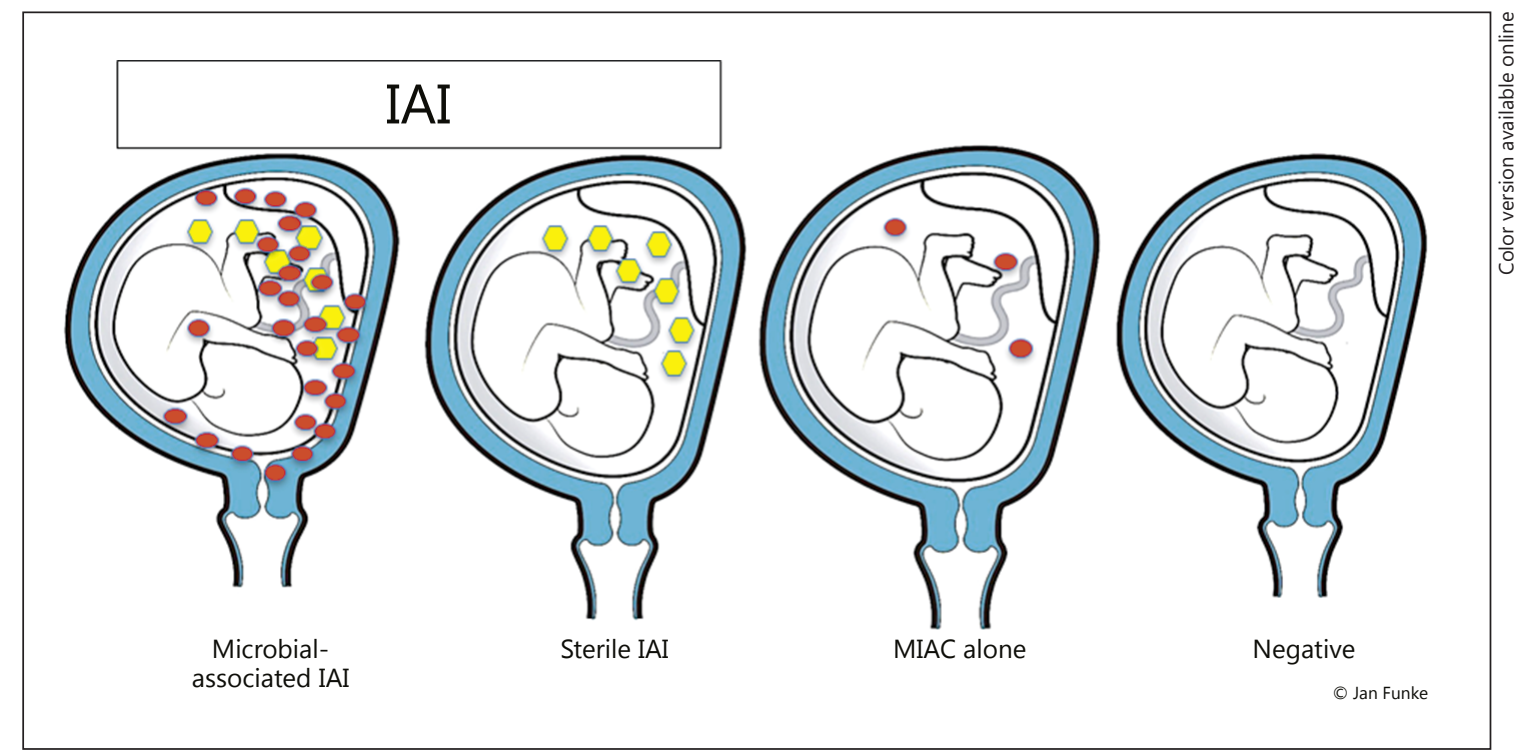

Fig. 2. Infectious and inflammatory phenotypes.

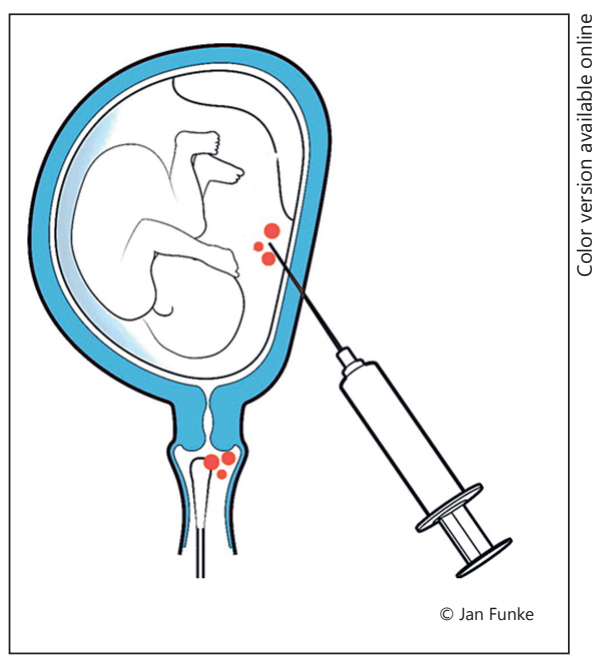

Fig. 3. Noninvasive sampling.

endogenous vaginal microbiome that protects against infection [14]. Indeed, Lactobacillus spp. lower the vaginal $\mathrm{pH}$ by producing lactic acid, creating an inhospitable environment for many pathogenic bacterial and viral species. Furthermore, frequent exfoliation of the superficial epithelium and interaction with mediators of innate and acquired immunity hold the key to a healthy vaginal environment [14].

Noninvasive Sampling of Intrauterine Infection
Complex genomic approaches, such as amplification and sequencing of the $16 \mathrm{~S}$ rRNA gene and bacterial community genes and genomes, are emerging to help us to better understand the complexity of the microbial ecosystem during gestation [15]. Thus, 6 community state types (CSTs) have been identified, 4 of which are Lactobacillusdominated (CST I, Lactobacillus crispatus; CST II, Lactobacillus gasseri; CST III, Lactobacillus iners; CST V, Lactobacillus jensenii). The remaining 2, CST IV-A (nonLactobacillus bacteria-dominated) and CST IV-B, are characterized by bacteria typically associated with bacterial vaginosis (Fig. 4).

Although the vaginal microbiome is less diverse but more stable in pregnant than in nonpregnant women [16-20], it modifies levels of cervical cytokines and chemokines during pregnancy. Thus, several authors have found both a lower expression of IL- $1 \beta$ and IL- 8 and a higher expression of the anti-inflammatory molecule secretory leukocyte protease inhibitor in women with a predominance of Lactobacillus-dominated CST [21-25]. Moreover, higher levels of cervical IL-8 have been reported in women in whom non-Lactobacillus bacteria were predominant [23]. The findings of authors evaluating inflammation in women with bacterial vaginosis have been more heterogeneous and sometimes contradictory. This heterogeneity of results is likely related to variation in microbiome composition, small sample sizes, and different study approaches [25-28]. Despite this limitation, a re- 


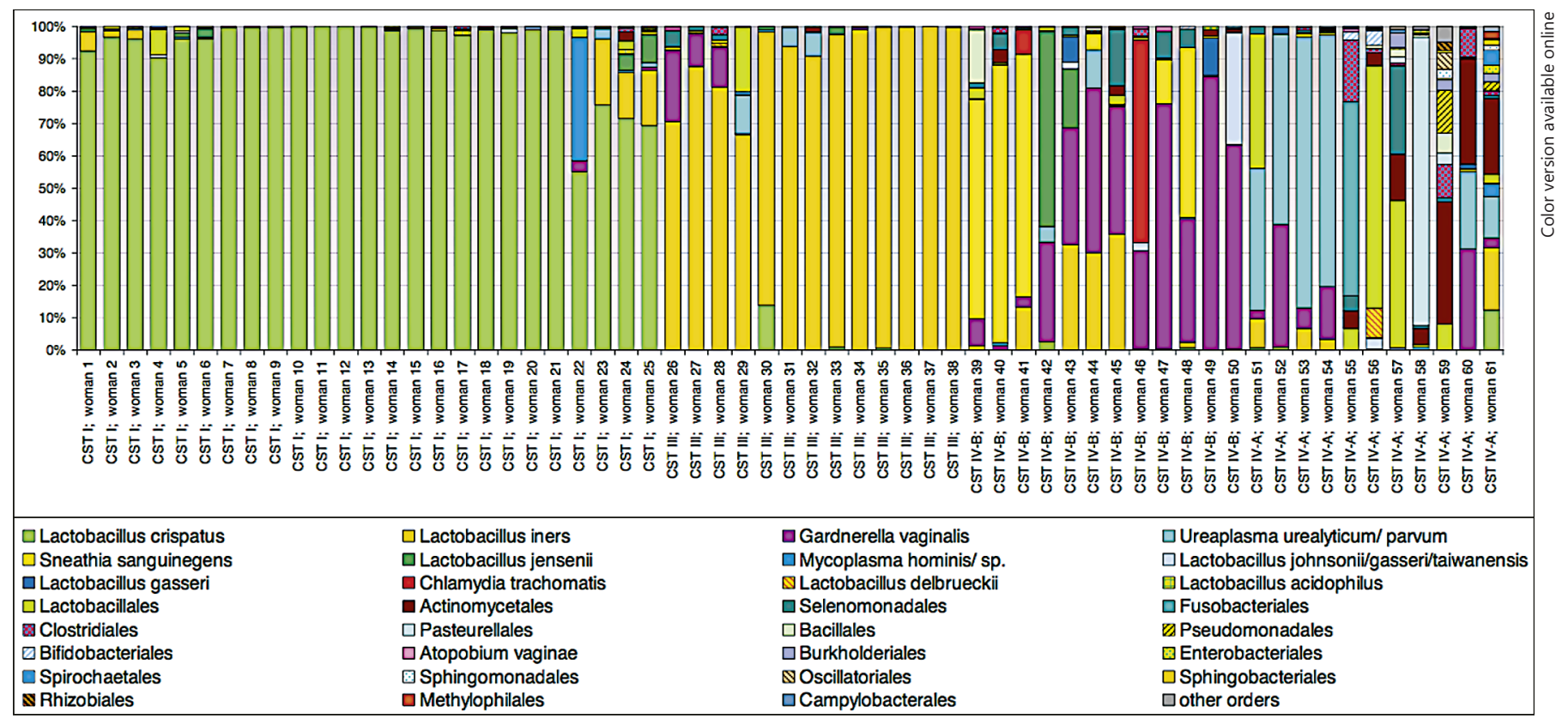

Fig. 4. Vaginal community state types (CSTs).

cent review by Mitchell and colleagues [25] concluded that the majority of published studies had found an increase in IL- $1 \beta$ levels and a decrease in secretory leukocyte protease inhibitor levels in women with bacterial vaginosis. However, no differences in the concentrations of other cytokines, such as tumor necrosis factor- $\alpha$, IL- 6 , or IL-8, had been observed [25-28].

\section{What Is the Best Approach to Diagnose Infection?}

In the majority of previous reports, the diagnosis of IAI is based on amniotic fluid culture results. However, this standard microbiological method diagnoses only a minor part of the multitude of these microorganisms, of which many are very difficult, or impossible, to cultivate. This limitation has led to the development of molecular methods that do not rely on cultivation. Molecular techniques provide a broader microorganism profile. These genomic techniques can be differentiated, based on the detection of specific bacterial fragments (e.g., polymerase chain reaction [PCR] for genital mycoplasma) and nonspecific conservative bacterial fragments of DNA (e.g., 16S rRNA gene fragments [29] or PCR-electrospray ionization mass spectrometry) $[9,30]$. We acknowledge that these molecular techniques show a high detection rate for noncultivatable microorganisms. However, it is important to highlight the fact that this approach cannot distinguish bacterial viability and that it can identify very small microbial loads of bacteria without any clinical relevance. Moreover, we acknowledge the difficulty to easily address these issues.

\section{The Role of Noninvasive Sampling in Women with Intra-Amniotic Infection}

\section{Cervical Mucus}

At the end of the nineties and the beginning of the new century, the major part of research was aimed at diagnosing infection of the amniotic fluid by separately analyzing cytokines or chemokines with enzyme-linked immunosorbent assay (ELISA) in noninvasively collected samples. Infection was confirmed based on aerobic/anaerobic bacteria culture or by PCR of genital mycoplasma, in both cases in amniotic fluid. There was no clear definition of IAI at that time.

In published studies, the cervical cytokine IL- 6 was the most often reported biomarker for infection. Supporting the theory of ascending infection, Jacobsson et al. [31] showed a relationship between cervical fluid IL- 6 and the presence of microorganisms between the chorioamniotic membranes. 
Table 1. Summary of the influence of cervical biomarkers on the diagnosis of intra-amniotic infection or inflammation (IAI) in women with PTL

\begin{tabular}{|c|c|c|c|c|c|c|}
\hline Reference & Biomarker & Analysis & Outcome & Methodology & Cut-off, ng/mL & AUC \\
\hline Holst et al. [32] & IL-6 & ELISA & $\begin{array}{l}\text { Infection } \\
\text { IAI }\end{array}$ & $\begin{array}{l}\text { Culture + PCR genital } \\
\text { mycoplasma } \\
\text { AF IL-6 }\end{array}$ & 1.7 & $\mathrm{~N} / \mathrm{A}$ \\
\hline Holst et al. [33] & IL-8 & & & & 6.7 & N/A \\
\hline Jacobsson et al. [36] & MCP-1 & ELISA & $\begin{array}{l}\text { Infection } \\
\text { IAI }\end{array}$ & $\begin{array}{l}\text { Culture + PCR genital } \\
\text { mycoplasma } \\
\text { AF IL-6 }\end{array}$ & $\begin{array}{l}0.80 \\
0.50\end{array}$ & $\begin{array}{l}\text { N/A } \\
\text { N/A }\end{array}$ \\
\hline Holst et al. [39] & $\begin{array}{l}\text { IL-17 + } \\
\text { MCP-1 }\end{array}$ & Multiplex immunoassay & Infection & $\begin{array}{l}\text { Culture + PCR genital } \\
\text { mycoplasma }\end{array}$ & $\begin{array}{l}0.025 \\
2.7\end{array}$ & 0.84 \\
\hline Ruetschi et al. [47] & $\begin{array}{l}\text { Human neutrophil } \\
\text { protein } 1-3 \\
\text { Calgranulin A } \\
\text { Calgranulin B }\end{array}$ & $\begin{array}{l}\text { SELDI-TOF } \\
\text { ELISA }\end{array}$ & IAI & AF IL-6 & $\begin{array}{l}\text { No differences } \\
\text { between groups }\end{array}$ & \\
\hline
\end{tabular}

IL, interleukin; AUC, area under the curve; AF, amniotic fluid; PTL, preterm labor, N/A, not available.

Several authors have reported that the diagnostic indices of IL-6 in cervical mucus to diagnose infection resemble those in amniotic fluid previously reported by Romero et al. [7]. Although different cutoff values for cervical IL-6 have been proposed, these authors reported sensitivities ranging from 66.8 to $92 \%$ and specificities ranging from 73.1 to $90.5 \%$. A strong correlation was observed between the cervical mucus and amniotic fluid levels of IL-6 [32-34].

We found fewer references for other cytokines, such as IL-18 [35], or chemokines, such as MCP-1 [36] or IL-8 $[32,37,38]$, all of which exhibited lower accuracy to diagnose infection than IL-6. A summary is shown in Table 1 .

The implementation of multiplexed immunoassay technology, at the beginning of the century, generated the possibility to simultaneously analyze an array of proteins using only small sample volumes $[39,40]$. Holst et al. [40] thus simultaneously evaluated 26 cytokines, chemokines, and neuropeptides in cervical mucus, including proteins previously reported after ELISA analysis (e.g., IL-6, IL-8, MCP-1, and IL-18). The authors aimed to compare different diagnostic models of infection in amniotic fluid and the cervical compartment, finding that the combination of cervical IL-17 and MCP-1 showed a good area under the curve (AUC), i.e., 0.87, to diagnose IAI. Regarding MCP-1, they found diagnostic indices similar to those reported years ago (sensitivity of $73 \%$ and specificity of $88 \%$ ) with ELISA analysis [36]. A list of relevant proteins for this multiplexed approach is provided in online Supplementary Appendix S1 (see www.karger.com/doi/10.1159/000480232 for all online suppl. material).

\section{Vaginal Fluid}

Reported findings concerning the expression of IL-6 in the vaginal compartment are more contradictory. On the one hand, Hitti et al. [41] only observed differences in the expression of vaginal IL-8, but not IL-6, using ELISA analysis. However, contrary results were reported by Park et al. [42] when they performed Bioplex cytokine array. After the introduction of multiplex immunoassay, 
Table 2. Summary of the influence of vaginal biomarkers on the diagnosis of intra-amniotic infection or inflammation (IAI) in women with PTL

\begin{tabular}{|c|c|c|c|c|c|c|}
\hline Reference & Biomarker & Analysis & Outcome & Methodology & $\begin{array}{l}\text { Cutoff, } \\
\mathrm{ng} / \mathrm{mL}\end{array}$ & AUC \\
\hline Hitti et al. [43] & $\begin{array}{l}\alpha_{1} \text {-acid glycoprotein }+ \\
\text { IGFBP-1 } \\
\text { Calgranulin C } \\
\text { Cystatin A }\end{array}$ & $\begin{array}{l}\text { Multidimensional liquid } \\
\text { chromatography, tandem mass } \\
\text { spectrometry and label-free } \\
\text { quantification } \\
\text { ELISA }\end{array}$ & Infection & Culture or AF IL- 6 & $\begin{array}{l}- \\
- \\
- \\
-\end{array}$ & 0.89 \\
\hline Park et al. [41] & $\begin{array}{l}\text { IL-6 } \\
\text { IL-8 }\end{array}$ & ELISA & Infection/IAI & $\begin{array}{l}\text { Culture } \\
\text { AF IL-6 }\end{array}$ & $\begin{array}{l}0.232 \\
7.815\end{array}$ & $\begin{array}{l}0.85 \\
0.69\end{array}$ \\
\hline
\end{tabular}

AUC, area under the curve; AF, amniotic fluid; PTL, preterm labor.

Combs et al. [43] explored 43 proteins, including IL-6 and IL-8. Their definition of infection was based on amniotic fluid cultures, 16S rRNA gene analysis and high levels of amniotic fluid IL-6. The authors concluded that the combination of IL-6, chemokine (CXC motif) ligand 1 , and insulin-like growth factor-binding protein (IGFBP-1) showed an AUC to diagnose infection of 0.87 . This AUC was, as expected, reduced to 0.78 when validated by ELISA. Interestingly, when the diagnostic accuracy of IL- 6 as a single biomarker was evaluated, these authors found a sensitivity of $79 \%$, a specificity of $78 \%$ and an AUC of 0.80 to diagnose infection, similar to the corresponding indices found years ago with ELISA analysis. The list of the proteins involved in this multiplex approach is presented in online Supplementary Appendix S1.

Mass spectrometry, with its capacity to detect small changes in protein and peptide abundance in response to an altered condition, constituted an alternative unbiased discovery approach. This contrasts with the previously extensively applied hypothesis-based biomarker discovery approach, based on immunoassay analysis. Hitti et al. [44] studied the proteome profile characterization of the vaginal compartment using multidimensional liquid chromatography, tandem mass spectrometry and labelfree quantification in a pooled strategy including women with IAI, early preterm birth and preterm labor. They defined infection based on amniotic fluid culture and amniotic fluid IL-6 levels. The authors validated candidate proteins with ELISA and identified 15 proteins differentially expressed in women with infection, including acute-phase reactants (such as $\alpha_{1}$-acid glycoprotein), immune modulators (such as calgranulin $\mathrm{C}$ and cystatin $\mathrm{A}$ ), high-abundance amniotic fluid proteins (such as IGFBP-1 and vitamin D-binding protein) and extracellular matrix-signaling factors (such as fatty acid-binding protein). After exploring the accuracy of diagnostic models, including different combinations of proteins, Hitti et al. [41] found that the combination of $\alpha_{1}$-acid glycoprotein with IGFBP-1, calgranulin $C$, and cystatin-A in the posterior vaginal fornix exhibited the strongest diagnostic value for infection (AUC 0.89). A summary of the influence of different reported biomarkers is shown in Table 2 .

\section{Maternal Blood}

There are few references exploring the maternal blood compartment in women with available information on amniotic fluid and although some authors $[45,46]$ have reported higher levels of some acute inflammatory biomarkers, such as IL-6 and C-reactive protein, in maternal blood, the observed inflammatory response was too weak to be taken into consideration in clinical practice. 
The Role of Noninvasive Sampling in Women with IAI

\section{Cervical Mucus}

To our knowledge, the Jacobsson group $[32,33]$ is the only one that has explored the association between cervical IL-6 concentrations and IAI, possibly partly due to the lack of a clear definition of IAI. Jacobsson et al. [47] defined IAI based on the best amniotic fluid IL- 6 cutoff value to predict spontaneous preterm delivery within 7 days. ELISA analysis of cervical IL-6 showed similar diagnostic indices for the outcome of IAI as for amniotic fluid sampling, i.e., $58 \%$ sensitivity and $83 \%$ specificity [32].

After the introduction of novel technologies, there has only been one published study that evaluated cervical mucus sampling for diagnosing IAI, using surface-enhanced laser desorption/ionization time-of-flight mass spectrometry (SELDI-TOF). Thus, Ruetschi et al. [48], of the Jacobsson group, observed significantly higher expressions of human neutrophil protein 1-3 and calgranulin A and B in the amniotic fluid of women with IAI, in a mixed population of cases with PTL and preterm prelabor rupture of membranes. However, they failed to reproduce these results when they tried to confirm these differences in the cervical compartment with SELDI-TOF and ELISA analysis.

\section{Maternal Blood}

Few reported studies have explored maternal blood as a surrogate for amniotic sampling to diagnose IAI, all of which evaluated a hypothesis-based candidate biomarker. Romero's group [49] reported that maternal serum adiponectin concentrations were lower in women with an episode of PTL, regardless of whether they delivered preterm or at term. They found the lowest concentrations in women with infection (based on amniotic fluid culture) or with IAI (based on amniotic fluid IL-6 levels). However, the same group did not find differences in levels of pentraxin-3 in maternal plasma [50] between women exposed and not exposed to this infectious/inflammatory condition. Finally, Park et al. [51] suggested maternal serum C-reactive protein as an independent predictor of IAI (based on amniotic fluid matrix metalloproteinase-8 levels). To our knowledge, no efforts have been made to reproduce these results.

\section{The Role of Noninvasive Sampling in Women with HCA}

So far, cervical IL- 8 has been the only chemokine suggested as an independent diagnostic biomarker for HCA in women with PTL. Rizzo et al. explored the capacity of cervical IL-8, clinical data [38], and fetal fibronectin [37] to identify HCA. A decade later, Holst et al. [52] also explored the corresponding diagnostic capacity of IL-8, in comparison to other different cervical interleukins and chemokines such as IL-6, IL-18, and MCP-1. Both authors concluded that IL-8 was an independent and strong diagnostic biomarker for HCA, with an AUC of 0.84 [38], a sensitivity ranging from 78 to $100 \%$, and a specificity around $67 \%[37,52]$.

\section{Discussion}

As mentioned above, Romero et al. [9] recently proposed distinguishing 4 infectious phenotypes of women with PTL, based on the amniotic fluid-derived information about infection and IAI. Combs et al. [2] observed that IAI was not simply present or absent in women with PTL, but also had degrees of severity correlating with early gestational age at admission, shorter latency to delivery and, therefore, with early delivery. Indeed, using the terminology suggested by Romero et al. [9], the subgroups with microbial-associated IAI and "sterile" IAI had the highest risks of spontaneous preterm delivery [2], with prevalences of 11 and $26 \%$, respectively.

We believe that there is no current justification to question the influence of IAI on the occurrence of spontaneous preterm delivery $[2,4,5,7]$. From our point of view, the clinical importance of performing amniocentesis to rule out infection or IAI is basically to identify the group with the highest risk, i.e., those who will inevitably deliver in the following days. This amniotic fluid-derived information may obviously help obstetricians manage these women. Indeed, information about amniotic fluid infection may render antenatal strategies such as tocolysis questionable. Moreover, amniotic fluid sampling may help obstetricians efficiently manage delivery and choose antenatal strategies, such as corticosteroids for lung maturation, magnesium sulfate for neuroprotection, transfer to a referral hospital, or antibiotics administration. Finally, it is indisputable that the information derived from amniotic fluid sampling, including type of microorganism, may help neonatologists implement the appropriate treatment of neonates.

We acknowledge that the invasive nature of amniocentesis limits clinical implementation. Furthermore, the prevalence of amniotic fluid infection in women with PTL, around $10-14 \%$, can probably not justify an amniocentesis in all women admitted with this diagnosis. There is also a lack of knowledge about the management of women with infection or IAI. 
Although noninvasive sampling seems promising, with an AUC to identify MIAC at $0.80-0.87$ in some cases $[40,41]$, no further translational research has been conducted. After more than 2 decades of research, there is still no consensus about which biomarker, alone or in combination, accurately predicts infection and IAI with optimal sensitivity and a sufficiently low false positivity rate to be implemented as a screening tool. In addition, there is no agreement about what approach and which cutoff are the most reproducible, for use in the worldwide clinical setting. Thus, despite the obvious improvement in technology, the diagnostic indices reported for the novel approaches have not substantially changed, compared with the classic hypothesis-based biomarker approach based on ELISA analysis.

Since not all women with PTL need an invasive approach to rule out an infectious/inflammatory condition, more efforts should be made by research groups with the experience to convert scientific knowledge into easy, cost-effective, reproducible and user-friendly tools to efficiently target the high-risk group that might benefit from amniocentesis. This review makes it evident that reproducing previous results should be the first step before exploring new emerging approaches. Spontaneous preterm birth is a burden and a problem worldwide, with enormous consequences for newborns, children and families. Screening of the intrauterine environment by noninvasive sampling should help us, as clinical researchers, to design larger clinical studies of targeted individual interventions, in order to evaluate the impact of infection or IAI on neonatal and long-term outcome.

\section{Disclosure Statement}

The authors report no conflict of interest.

\section{References}

1 Rodriguez-Trujillo A, Cobo T, Vives I, Bosch J, Kacerovsky M, et al: Gestational age is more important for short-term neonatal outcome than microbial invasion of the amniotic cavity or intra-amniotic inflammation in preterm prelabor rupture of membranes. Acta Obstet Gynecol Scand 2016;95:926-933.

2 Combs CA, Gravett M, Garite TJ, Hickok DE, Lapidus J, et al: Amniotic fluid infection, inflammation, and colonization in preterm labor with intact membranes. Am J Obstet Gynecol 2014;210:125.e1-125.e15.

3 Shim SS, Romero R, Hong JS, Park CW, Jun $\mathrm{JK}$, et al: Clinical significance of intra-amniotic inflammation in patients with preterm premature rupture of membranes. Am J Obstet Gynecol 2004;191:1339-1345.

4 Yoon BH, Romero R, Moon JB, Shim SS, Kim $\mathrm{M}$, et al: Clinical significance of intra-amniotic inflammation in patients with preterm labor and intact membranes. Am J Obstet Gynecol 2001;185:1130-1136.

5 Jacobsson B, Mattsby-Baltzer I, Andersch B, Bokstrom H, Holst RM, et al: Microbial invasion and cytokine response in amniotic fluid in a Swedish population of women in preterm labor. Acta Obstet Gynecol Scand 2003;82: 120-128.

6 Cobo T, Palacio M, Navarro-Sastre A, Ribes A, Bosch J, et al: Predictive value of combined amniotic fluid proteomic biomarkers and interleukin-6 in preterm labor with intact membranes. Am J Obstet Gynecol 2009;200:499. e1-6.
7 Romero R, Yoon BH, Mazor M, Gomez R, Diamond MP, et al: The diagnostic and prognostic value of amniotic fluid white blood cell count, glucose, interleukin-6, and gram stain in patients with preterm labor and intact membranes. Am J Obstet Gynecol 1993;169: 805-816.

8 Romero R, Chaiworapongsa T, Alpay Savasan $\mathrm{Z}, \mathrm{Xu} Y$, Hussein Y, et al: Damage-associated molecular patterns (DAMPs) in preterm labor with intact membranes and preterm PROM: a study of the alarmin HMGB1. J Matern Fetal Neonatal Med 2011;24:1444-1455.

9 Romero R, Miranda J, Chaiworapongsa T, Korzeniewski SJ, Chaemsaithong P, et al: Prevalence and clinical significance of sterile intra-amniotic inflammation in patients with preterm labor and intact membranes. Am J Reprod Immunol 2014;72:458-474.

10 Triunfo S, Parra-Saavedra M, RodriguezSureda V, Crovetto F, Dominguez C, et al: Angiogenic factors and Doppler evaluation in normally growing fetuses at routine third-trimester scan: prediction of subsequent low birth weight. Fetal Diagn Ther 2016;40:13-20.

11 Kim SY, Kim HJ, Park SY, Han YJ, Choi JS, et al: Early prediction of hypertensive disorders of pregnancy using cell-free fetal DNA, cellfree total DNA, and biochemical markers. Fetal Diagn Ther 2016;40:255-262.

12 Yefet E, Kuzmin O, Schwartz N, Basson F, Nachum Z: Predictive value of second-trimester biomarkers and maternal features for adverse pregnancy outcomes. Fetal Diagn Ther 2017, Epub ahead of print.
13 Becher N, Adams Waldorf K, Hein M, Uldbjerg N: The cervical mucus plug: structured review of the literature. Acta Obstet Gynecol Scand 2009;88:502-513.

14 Anderson DJ, Marathe J, Pudney J: The structure of the human vaginal stratum corneum and its role in immune defense. Am J Reprod Immunol 2014;71:618-623.

15 Santolaya-Forgas J, Townsend R, Santolaya JL, Patel P, Herrera-Garcia G, et al: The microbiota and transgenomic networks: potential implications for maternal-fetal medicine. Fetal Diagn Ther 2016;39:1-3.

16 Aagaard K, Riehle K, Ma J, Segata N, Mistretta TA, et al: A metagenomic approach to characterization of the vaginal microbiome signature in pregnancy. PLoS One 2012;7:e36466.

17 Hernandez-Rodriguez C, Romero-Gonzalez R, Albani-Campanario M, Figueroa-Damian $\mathrm{R}$, Meraz-Cruz N, et al: Vaginal microbiota of healthy pregnant Mexican women is constituted by four Lactobacillus species and several vaginosis-associated bacteria. Infect Dis Obstet Gynecol 2011;2011:851485.

18 Hyman RW, Fukushima M, Jiang H, Fung E, Rand L, et al: Diversity of the vaginal microbiome correlates with preterm birth. Reprod Sci 2014;21:32-40.

19 Romero R, Hassan SS, Gajer P, Tarca AL, Fadrosh DW, et al: The composition and stability of the vaginal microbiota of normal pregnant women is different from that of non-pregnant women. Microbiome 2014;2:4. 
20 Verstraelen H, Verhelst R, Claeys G, De Backer E, Temmerman M, et al: Longitudinal analysis of the vaginal microflora in pregnancy suggests that $L$. crispatus promotes the stability of the normal vaginal microflora and that L. gasseri and/or L. iners are more conducive to the occurrence of abnormal vaginal microflora. BMC Microbiol 2009;9:116.

21 Orfanelli T, Jayaram A, Doulaveris G, Forney LJ, Ledger WJ, et al: Human epididymis protein 4 and secretory leukocyte protease inhibitor in vaginal fluid: relation to vaginal components and bacterial composition. Reprod Sci 2014;21:538-542.

22 Kyongo JK, Jespers V, Goovaerts O, Michiels J, Menten J, et al: Searching for lower female genital tract soluble and cellular biomarkers: defining levels and predictors in a cohort of healthy Caucasian women. PLoS One 2012; 7:e43951.

23 Sakai M, Ishiyama A, Tabata M, Sasaki Y, Yoneda S, et al: Relationship between cervical mucus interleukin- 8 concentrations and vaginal bacteria in pregnancy. Am J Reprod Immunol 2004;52:106-112.

24 Nikolaitchouk N, Andersch B, Falsen E, Strombeck L, Mattsby-Baltzer I: The lower genital tract microbiota in relation to cytokine-, SLPI- and endotoxin levels: application of checkerboard DNA-DNA hybridization (CDH). APMIS 2008;116:263-277.

25 Mitchell C, Marrazzo J: Bacterial vaginosis and the cervicovaginal immune response. Am J Reprod Immunol 2014;71:555-563.

26 Balkus J, Agnew K, Lawler R, Mitchell C, Hitti J: Effects of pregnancy and bacterial vaginosis on proinflammatory cytokine and secretory leukocyte protease inhibitor concentrations in vaginal secretions. J Pregnancy 2010; 2010:385981.

27 Beigi RH, Yudin MH, Cosentino L, Meyn LA, Hillier SL: Cytokines, pregnancy, and bacterial vaginosis: comparison of levels of cervical cytokines in pregnant and nonpregnant women with bacterial vaginosis. J Infect Dis 2007;196:1355-1360.

28 Marconi C, Donders GG, Parada CM, Giraldo PC, da Silva MG: Do Atopobium vaginae, Megasphaera sp. and Leptotrichia sp. change the local innate immune response and sialidase activity in bacterial vaginosis? Sex Transm Infect 2013;89:167-173.

29 Musilova I, Kutova R, Pliskova L, Stepan M, Menon R, et al: Intraamniotic inflammation in women with preterm prelabor rupture of membranes. PLoS One 2015;10:e0133929.

30 Romero R, Miranda J, Chaemsaithong P, Chaiworapongsa T, Kusanovic JP, et al: Sterile and microbial-associated intra-amniotic inflammation in preterm prelabor rupture of membranes. J Matern Fetal Neonatal Med 2015;28:1394-1409.

31 Jacobsson B, Mattsby-Baltzer I, Hagberg H: Interleukin-6 and interleukin-8 in cervical and amniotic fluid: relationship to microbial invasion of the chorioamniotic membranes. BJOG 2005;112:719-724.
32 Holst RM, Mattsby-Baltzer I, Wennerholm UB, Hagberg H, Jacobsson B: Interleukin-6 and interleukin- 8 in cervical fluid in a population of Swedish women in preterm labor: relationship to microbial invasion of the amniotic fluid, intra-amniotic inflammation, and preterm delivery. Acta Obstet Gynecol Scand 2005;84:551-557.

33 Holst RM, Jacobsson B, Hagberg H, Wennerholm UB: Cervical length in women in preterm labor with intact membranes: relationship to intra-amniotic inflammation/microbial invasion, cervical inflammation and preterm delivery. Ultrasound Obstet Gynecol 2006;28:768-774.

34 Rizzo G, Capponi A, Rinaldo D, Tedeschi D, Arduini D, et al: Interleukin- 6 concentrations in cervical secretions identify microbial invasion of the amniotic cavity in patients with preterm labor and intact membranes. Am J Obstet Gynecol 1996;175:812-817.

35 Jacobsson B, Holst RM, Mattsby-Baltzer I, Nikolaitchouk N, Wennerholm UB, et al: Interleukin-18 in cervical mucus and amniotic fluid: relationship to microbial invasion of the amniotic fluid, intra-amniotic inflammation and preterm delivery. BJOG 2003;110:598603.

36 Jacobsson B, Holst RM, Wennerholm UB, Andersson B, Lilja H, et al: Monocyte chemotactic protein-1 in cervical and amniotic fluid: relationship to microbial invasion of the amniotic cavity, intra-amniotic inflammation, and preterm delivery. Am J Obstet Gynecol 2003;189:1161-1167.

37 Rizzo G, Capponi A, Vlachopoulou A, Angelini E, Grassi C, et al: The diagnostic value of interleukin-8 and fetal fibronectin concentrations in cervical secretions in patients with preterm labor and intact membranes. J Perinat Med 1997;25:461-468.

38 Rizzo G, Capponi A, Vlachopoulou A, Angelini E, Grassi C, et al: Ultrasonographic assessment of the uterine cervix and interleukin-8 concentrations in cervical secretions predict intrauterine infection in patients with preterm labor and intact membranes. Ultrasound Obstet Gynecol 1998;12:86-92.

39 Gravett MG, Thomas A, Schneider KA, Reddy AP, Dasari S, Jacob T, Lu X, Rodland M, Pereira L, Sadowsky DW, Roberts CT Jr, Novy MJ, Nagalla SR: Proteomic analysis of cervical-vaginal fluid: identification of novel biomarkers for detection of intra-amniotic infection. J Proteome Res. 2007;6:89-96.

40 Holst RM, Hagberg H, Wennerholm UB, Skogstrand K, Thorsen P, et al: Prediction of microbial invasion of the amniotic cavity in women with preterm labour: analysis of multiple proteins in amniotic and cervical fluids. BJOG 2011;118:240-249.

41 Hitti J, Hillier SL, Agnew KJ, Krohn MA, Reisner DP, et al: Vaginal indicators of amniotic fluid infection in preterm labor. Obstet Gynecol 2001;97:211-219.
42 Park JW, Park KH, Lee SY: Noninvasive prediction of intra-amniotic infection and/or inflammation in women with preterm labor: various cytokines in cervicovaginal fluid. Reprod Sci 2013;20:262-268.

43 Combs CA, Garite TJ, Lapidus JA, Lapointe JP, Gravett M, et al: Detection of microbial invasion of the amniotic cavity by analysis of cervicovaginal proteins in women with preterm labor and intact membranes. Am J Obstet Gynecol 2015;212:482.e1-482.e12.

44 Hitti J, Lapidus JA, Lu X, Reddy AP, Jacob $T$, et al: Noninvasive diagnosis of intraamniotic infection: proteomic biomarkers in vaginal fluid. Am J Obstet Gynecol 2010;203:32. e1-8.

45 Dulay AT, Buhimschi IA, Zhao G, Bahtiyar MO, Thung SF, et al: Compartmentalization of acute phase reactants interleukin-6, C-reactive protein and procalcitonin as biomarkers of intra-amniotic infection and chorioamnionitis. Cytokine 2015;76:236-243.

46 Cobo T, Tsiartas P, Kacerovsky M, Holst RM, Hougaard DM, et al: Maternal inflammatory response to microbial invasion of the amniotic cavity: analyses of multiple proteins in the maternal serum. Acta Obstet Gynecol Scand 2013;92:61-68.

47 Jacobsson B, Mattsby-Baltzer I, Andersch B, Bokstrom H, Holst RM, et al: Microbial invasion and cytokine response in amniotic fluid in a Swedish population of women with preterm prelabor rupture of membranes. Acta Obstet Gynecol Scand 2003;82:423-431.

48 Ruetschi U, Rosen A, Karlsson G, Zetterberg $\mathrm{H}$, Rymo L, et al: Proteomic analysis using protein chips to detect biomarkers in cervical and amniotic fluid in women with intra-amniotic inflammation. J Proteome Res 2005;4: 2236-2242.

49 Mazaki-Tovi S, Romero R, Vaisbuch E, Erez O, Mittal P, et al: Dysregulation of maternal serum adiponectin in preterm labor. J Matern Fetal Neonatal Med 2009;22:887-904.

50 Cruciani L, Romero R, Vaisbuch E, Kusanovic JP, Chaiworapongsa T, et al: Pentraxin 3 in maternal circulation: an association with preterm labor and preterm PROM, but not with intra-amniotic infection/inflammation. J Matern Fetal Neonatal Med 2010;23:10971105.

51 Park CW, Yoon BH, Park JS, Jun JK: An elevated maternal serum $\mathrm{C}$-reactive protein in the context of intra-amniotic inflammation is an indicator that the development of amnionitis, an intense fetal and AF inflammatory response are likely in patients with preterm labor: clinical implications. J Matern Fetal Neonatal Med 2013;26:847-853.

52 Holst RM, Laurini R, Jacobsson B, Samuelsson E, Savman K, et al: Expression of cytokines and chemokines in cervical and amniotic fluid: relationship to histological chorioamnionitis. J Matern Fetal Neonatal Med 2007;20:885-893. 